\title{
Desarrollos apocalípticos y místicos de algunas expresiones bíblicas ${ }^{1}$
}

\author{
Guadalupe SEIJAS DE LOS RÍOS-ZARzosA \\ Universidad Complutense, Madrid
}

Pocas sensaciones son tan comunes a todo ser humano como el miedo ${ }^{2}$. No existe civilización ni cultura que no haya intentado enfrentarse de una u otra forma a sus terrores más primitivos. El miedo paraliza, produce escalofríos, eriza la piel, provoca frío y calor a la vez, nos hace escuchar voces..., todas ellas sensaciones que, a menudo, hacen perder serenidad y raciocinio.

La Biblia no es una excepción a esta realidad. En ella encontramos algunos textos que nos hablan de miedo en sus múltiples variantes: miedo a la noche, miedo a la oscuridad, miedo a demonios, miedo al día del juicio, etc.

La finalidad de este artículo es analizar algunas de estas expresiones en la Biblia, atendiendo al aspecto lingüístico y mitológico, para después estudiar su desarrollo en otras etapas de la literatura judía. El trabajo se estructura en dos partes. La primera se centra en las expresiones bíblicas y accede al significado de éstas desde una perspectiva fundamentalmente filológica. Para ello tengo en cuenta el contexto, otros lugares donde aparece el mismo término, expresiones similares, los posibles vínculos con la mitología meso-

\footnotetext{
${ }^{1}$ Parte de este artículo fue presentado en el XVII congreso de IOSOT (Basilea, 5-10 de agosto de 2001).

${ }^{2}$ Quisiera agradecer al Dr. J. Trebolle Barrera el que me propusiera la idea de este artículo y a la Dra. A. Alba Cecilia sus orientaciones y sugerencias relativas al campo de la mística.

Sefarad 62 (2002) págs. 169-183

(c) CSIC

ISSN 037-0894
} 
potámica y ugarítica, etc. La segunda parte analiza textos apocalípticos y místicos desde un punto de vista temático. En este sentido, no hay que olvidar que estos textos emplean una pluralidad de palabras y expresiones, lo que hace que el estudio lingüístico de las mismas exceda con mucho del propósito de este trabajo.

La investigación se ha centrado en los términos מעת צ'tiempo de angustia', מלך בלהות 'rey de terrores' (Iob 18,14) y פחד לילה 'כh 'terror de la noche' (Ps 91,5).

\section{ESTUDIO FILOLÓGICO}

\section{I.1. La expresión עת צרה}

El sustantivo צרה de la raíznifica 'estrechez' pero también 'aprieto', 'apuro', 'peligro', 'tribulación', 'angustia', 'aflicción', ‘triste-

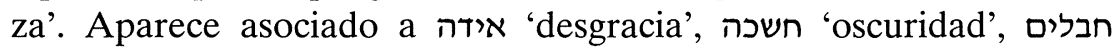
'espasmos', יגון 'tristeza', צוקה 'estrechez' y רעה 'desgracia'.

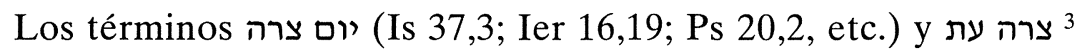
tienen el significado de 'día de angustia', 'día de peligro', 'día acia-

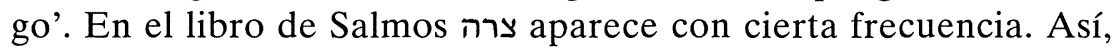
בעת צרה (Ps 37,39), לעתות צרה (Ps 9,10; 10,1), ביום צר (Ps 102,3), entre otros.

Se puede afirmar que עת צרה y otras expresiones afines se relacionan con la literatura profética precedente y con la literatura apocalíptica posterior. La designación 'el día del Señor' o 'el día de Yahvéh' aparece fundamentalmente en Isaías, Joel y Sofonías. Este día se describe como un día de oscuridad y no de luz: «Día de tiniebla y oscuridad, día de nubes y densa niebla» ${ }^{4}$ (Ioel 2,1-2; cf. también Am 5,18-20), un día de combate. Un día relativamente próximo en el que Yahvéh castigará a los enemigos de su pueblo, pero también a Israel por haber transgredido la alianza. Podemos citar, entre otras expresiones del mismo tipo, 'día de la ira' (Sof 2,2 ), 'día de la desgracia' (Ier 51,2) y 'en aquel día' (Is 11,10; Ier 25,33; Zach 9,16; etc.), que aparece con mayor frecuencia.

3 Cf. J. Trebolle Barrera, El libro de los Salmos. Religión, poder y saber (Madrid 2001) págs. 261-262.

${ }^{4}$ Las traducciones han sido tomadas de F. CANTERA y M. IGLESIAS, Sagrada Biblia (2a ed. Madrid 1979). 
Un desarrollo secundario nos conduce a un día de juicio cósmico y universal que enlaza con la literatura apocalíptica y la escatología, y subraya la idea, característica de este tipo de literatura, de los terrores del fin del mundo. Con este sentido aparece en Qumrán ${ }^{5}$, junto a otros términos similares como 'últimos tiempos', 'tiempos de prueba', 'tiempos de impiedad'.

En el Nuevo Testamento 'el tiempo de la tribulación' se describe como día de angustia y aflicción: «pues habrá entonces una gran tribulación, como no la ha habido desde el principio del mundo» (Mt 24,21) ${ }^{6}$. El 'día de Yahvéh' en los Evangelios es un día de juicio ${ }^{7}$, donde se discrimina entre buenos y malos; un día de tinieblas para los pecadores y de luz para los justos. Ese día tendrá lugar al final de los tiempos y se caracterizará por ser un día terrible, de destrucción cósmica.

\section{I.2. La expresión מלך בלהות}

El término 'rey de los terrores' corresponde a Iob 18,14 y aparece una sola vez en el Antiguo Testamento: «Es arrancado de su tienda [que era su seguro], y puedes conducirle al rey de los terrores». El sustantivo בלהה, que significa 'terror', proviene de la raíz בלה. En el libro de Job siempre aparece en plural $(18,11.14$ 24,17;27,20; 30,15). La palabra בלהה se asocia con la idea de destrucción. Específicamente en Iob 24,17 aparece en conexión con צלמות en una alusión al mundo de la muerte, al Sheol. En Iob 10,21 encontramos una descripción de este lugar «tierra de negrura <como oscuridad, sombraf $>$ y desórdenes, y donde la claridad misma es cual la oscuridad».

Numerosos autores han dedicado gran esfuerzo e interés a encontrar alguna divinidad del Próximo Oriente que pudiera identificarse con este término. Algunos han concedido una relevancia significativa a la expresión בכור מות 'primogénito de la muerte', que aparece en Iob 18,13 («comerá las partes de su piel, comerá sus miembros el primogénito de la muerte»), entendiendo que ambas expresiones se refieren al mismo personaje, si bien no existe unanimidad en este sentido.

${ }^{5}$ Cf. Regla de la Guerra (15,1); Peser de salmos (4Q171 [4QpPsa] frags. 3-10, col. 15-19) y en $4 \mathrm{Q} 460=4$ Qpseudepigraphic Works frag. 1,11 .

${ }^{6}$ Véase también el v.29 y el paralelo de Mc 13,19.

${ }^{7}$ Cf. Mt 10,5; 11,22.24, etc. 
En esta línea se observan dos planteamientos: el que defiende un sustrato babilónico y el que percibe un trasfondo cananeo. Entre los defensores de la influencia babilónica están los que identifican מלך בלהות con el dios Nergal, rey del inframundo y esposo de Ereškigal, figura que inspira terror, o con la propia Ereškigal, la reina del inframundo ${ }^{8}$. Otros entienden que se refiere a Namtaru, primogénito de Ereškigal, dios de la pestilencia y de las plagas, visir del mundo subterráneo ${ }^{9}$.

Algunos investigadores consideran más acertado encontrar una posible conexión con la mitología ugarítica, más próxima en el espacio y en el tiempo al entorno bíblico, y defienden que detrás de este término se encuentra la figura del hijo de Mot ${ }^{10} \mathrm{o}$ del propio Mot, dios de la muerte y del inframundo ${ }^{11}$.

\section{I.3. La expresión פחר לילה}

Por último, el término פחר לילה 'terror de la noche' que aparece en Ps 91,5, también es happax legomenon. La mayoría de los estudiosos están de acuerdo en afirmar que este término se refiere a un ser demoniaco que actúa por la noche. En este sentido, el contexto inmediato (v.6) recoge las palabras דבר 'peste', 'epidemia', קטר 'destrucción', ישור צהרים 'azote que devasta a mediodía', todos ellos términos que están en relación con demonios que actúan en las distintas fases del día: mañana, mediodía, tarde y noche/medianoche. En el v.13 aparece la 'serpiente' פתן, 'dragones marinos' שחל ' שגין, 'león 'leoncillos' כפיר. Estas dos últimas pala-

\footnotetext{
${ }^{8}$ W. A. IRWIN, «Job's redeemer», JBL 81 (1962) págs. 217-219.

9 J. B. BuRNS, «The Identity of Death's First-Born (Job XVII 13)», VT 37 (1987) págs. 362-364: «The image conveyed is quite clear. The 'First-Born of Death', Namtar, god of pestilence, lays hold on the wicked man, devours his skin with burning fevers, consumes his shrivelled limbs and drags him before Nergal, king of the underworld and husband to Ereshkigal, the mother of Namtar.» (pág. 364).

${ }^{10}$ N. S. SARNA, «The Mythological Background of Job 18», JBL 82 (1963) págs. 315-318, aunque él mismo reconoce que no existe ninguna mención específica al hijo de Mot en la literatura ugarítica.

${ }^{11} \mathrm{~N}$. WyATT, "The Expression bekor mawet in Job XVIII 13 and its Mythological Background», VT 40 (1990) págs. 207-216.
} 
bras posiblemente se refieran a demonios con cabeza de león ${ }^{12}$. Igualmente, en el salmo encontramos determinados verbos que suelen aparecer en relación con las actividades de los demonios: שרך 'asolar, devastar', נרר 'caminar, marchar' נגש 'aproximar, acercar' y קרב 'acercar'. En relación con este aspecto es interesante observar que, dentro de la liturgia judía, este salmo se recitaba antes de dormir para evitar encuentros con demonios ${ }^{13}$.

Los principales rasgos de este demonio quedan recogidos en la expresión פחר לילה. De un lado el terror y, de otro, el ámbito en el que actúa: la noche-oscuridad. Estas características aparecen más desarrolladas en Iob 18,5-21, donde se muestran conjuntamente la oscuridad que cae sobre el malvado y el terror que le atrapa. Algunos textos bíblicos son muy ilustrativos al respecto, ya que reflejan las sensaciones físicas ocasionadas por el pavor. En Iob 4,12-16a, 'Elifaz es aterrorizado por una visión nocturna y se nos muestra paralizado y colapsado por el miedo:

12 «Ahora bien, una palabra se me dice a hurtadillas y mi oreja capta de ella el susurro;

${ }^{13}$ en las pesadillas originadas por visiones nocturnas, cuando cae un sopor sobre los hombres,

14 un temblor me ha sobrevenido y un escalofrío, y todos mis huesos ha hecho estremecer.

${ }^{15}$ Una ráfaga de viento se desliza sobre mi faz, eriza el pelo de mi carne;

16 [algo] se para... y no reconozco su semblante». ${ }^{14}$

El capítulo 17 del libro de la Sabiduría ${ }^{15}$ describe la plaga de las tinieblas. He seleccionado algunos versículos que detallan pormenorizadamente aspectos asociados al miedo a la noche, tales como lo impenetrable de la oscuridad, los sonidos que inquietan, el desmadejamiento, etc.

${ }^{4}$ «que ni el rincón que los retenía los mantuvo sin miedo.

Ecos perturbadores les resonabanc alrededor,

12 M. MALUL, «Terror of Night», en Dictionary of Deities and Demons in the Bible, eds. K. VAN DER TOORN, B. BECKING y P. W. VAN DER HORST (Leiden New York - Köln 1995) cols. 1603-1608.

13 M. MALUL, «Terror of Night», col. 1605.

${ }^{14}$ F. Cantera y M. Iglesias, Sagrada Biblia, pág. 690.

15 L. Alonso Schökel y C. CARniti, Comentario a Salmos, vol. 2 (Navarra 1992) pág. 1190. 
Y espectros abatidos se aparecían con lúgubres semblantes.

${ }^{5}$ El fuego era incapaz de alumbrar,

y los resplandores fulgurantes de las estrellas

no valían para iluminar aquella noche tenebrosa.

${ }^{14}$ Pero ellos aquella noche en verdad impotente, salida de las entretelas del Hades potente, mientras dormían el mismo sueño,

${ }^{15}$ bien eran expulsados por portentos de espectros,

o bien desfallecían rindiendo su alma;

porque un temor repentino e inesperado ese derramóe sobre ellos» ${ }^{16}$.

A pesar de ser una expresión que aparece una sola vez en la Biblia, las palabras פחר לילה y aparecen juntas en otras dos ocasiones: Deut 28,66 מפח עדת לילה עy noche y día temerás sin estar seguro de tu vida» y Cant 3,8 מפחד בלילות "por temor a sorpresas nocturnas». En el caso del Cantar se refleja la creencia en demonios de la noche y espíritus malvados que acechaban a la pareja para causarle daño, especialmente durante la relación sexual.

Al igual que en Iob 18,14 , se ha buscado identificar esta expresión con algún demonio concreto. Las que más se adecuan a las características que acabamos de mencionar son las diosas mesopotámicas Lilû y Lilìtu, demonios que atacaban a las mujeres embarazadas y a los recién nacidos. Este tipo de demonios femeninos alados ya se conocían en el entorno cananeo-hebreo, como lo demuestra una inscripción encontrada en Arslan-Tash, en el norte de Siria, datada entre los siglos VIII-VII a.C. Se describe como una joven muchacha que no ha alcanzado la madurez y que deambula por las calles en busca de compañía masculina. Es una perpetua seductora de hombres, siempre insatisfecha sexualmente. En la demonología judía tiene su correspondencia con Lilith, donde desempeña un papel central. Lilith es un buen ejemplo de demonio que durante siglos ha inspirado miedo y pavor, actuando sobre todo en la noche. Las leyendas atribuidas a ella se han desarrollado en dos planos, el popular y folclórico (Lilith, que ataca a los recién nacidos y a los novios), y el místico-cabalístico (Lilith, reina del mal). Merece la pena que nos detengamos en este punto.

${ }^{16}$ F. Cantera y M. Iglesias, Sagrada Biblia, pág. 935. 
La única referencia a Lilith en el Antiguo Testamento es Is 34,14 , donde aparece entre las bestias de presa y los espíritus que asolarán la tierra en el día de la venganza. En el Talmud ${ }^{17}$, Lilith aparece con pelo largo y alas y aullando sin cesar. Se advierte a los hombres que duermen solos de que pueden ser atrapados por ella.

En la literatura midrásica tomó cuerpo una tradición según la cual Lilith fue la primera esposa de Adán. Esta leyenda ${ }^{18}$ aparece en el Alfabeto de Ben Sira, que es un midrash del periodo gaónico ${ }^{19}$.

Como ya se ha mencionado con anterioridad, en la demonología cabalística Lilith adquiere algunos rasgos propios. Mantiene las características de estranguladora de niños y seductora de hombres, con cuyas poluciones nocturnas tiene un número indefinido de hijos. En el Zohar se le atribuyen los apelativos de ramera, malvada, falsa y negra ${ }^{20}$. Es una de las cuatro madres de los demonios junto con Agrat, Mahalath y Naamah. Pero sin lugar a dudas el

${ }^{17}$ Cf. 'Erub. 100b; Nid 24b; Shab 151 b y B. Bat $73^{a}$.

18 En ella se narra que Lilith y Adán fueron creados de la tierra al mismo tiempo. Inmediatamente, Lilith empezó a discutir con Adán acerca de quién debía estar debajo durante la relación sexual, defendiendo que ambos eran iguales, pues habían sido creados de la tierra a la vez. Pronunciando el nombre del Inefable, Lilith se elevó por el aire. A petición de Adán, el Altísimo envió tras ella a tres ángeles, Snwy, Snsnwy y Smnglf, que la encontraron en el Mar Rojo. Los ángeles la amenazaron con matar cada día a cien de sus hijos si ella no regresaba. Ella protestó aduciendo que había sido expresamente creada para hacer daño a los recién nacidos, pudiendo hacerlo hasta el octavo día a partir de su nacimiento si era varón y hasta el duodécimo si era hembra. Sin embargo, tuvo que aceptar que cada vez que viera la imagen de estos ángeles en un amuleto perdería su poder sobre los niños. De aquí surgió la costumbre de fabricar amuletos para contrarrestar sus efectos nocivos en recién nacidos y durante el momento del parto, costumbre muy difundida en la Edad Media, especialmente entre los judíos askhenazíes, y que ha perdurado hasta tiempos relativamente cercanos (s. XVIII). Los amuletos consistían en pedazos de papel, pergamino o discos de metal en los que se consignaban fórmulas que protegían al portador del mal de ojo de enfermedades y de todo tipo de desgracias. Cf. «Amulets», en Encyclopedia Judaica, vol. 2 cols. 906-915.

${ }^{19}$ En realidad, debería denominarse Pseudo ben Sirah. Cf. E. YASSIF, Pseudo ben Sira. The Text, its Literary Character and Status in the History of the Hebrew Story in the Middle Ages (en hebreo) 2 vols. Tesis doctoral (Jerusalem 1977).

${ }^{20}$ Zohar I, 14b; 54b; II, 96 ${ }^{\mathrm{a}} .111^{\mathrm{a}}$; III, 19 ${ }^{\mathrm{a}} .76 \mathrm{~b}$. Para una descripción pormenorizada de Lilith, cf. Zohar I, 148 ${ }^{\mathrm{a}}$-148b: I. TISHBY, The Wisdom of the Zohar, 3 vols. (Oxford 1989). 
aspecto más novedoso es el hecho de que aparece como reina de las fuerzas del mal y se convierte en la madre de un pueblo impuro ${ }^{21}$. Lilith aparece por primera vez en la Cábala como la compañera de Samael, con el que forma una pareja de seres demoniacos. Juntos constituyen una especie de alter ego de la pareja formada por Adán y Eva. Samael ${ }^{22}$-cuyo nombre significa «veneno de Dios»- es uno de los ángeles caídos. Aparece como rey de los demonios y encarnación de todo tipo de perversidades. Tiene a su cargo un ejército de seres demoniacos y sus acciones están encaminadas a destruir al hombre y a provocar la muerte. Esta concepción aparece recogida en las fuentes que emplea Isaac ben Jacob ha-Cohen (segunda mitad del s. XIII) en su Ma'mar 'al ha-'asilut ha-sěma'lit (el tratado del lado izquierdo de las Sefirot), y en 'Ammud ha-Sěmali, obra de su discípulo Moseh ben Solomon ben Simeon de Burgos. En la obra de estos dos cabalistas, así como posteriormente en el Tikkunê Zohar, cristaliza la idea de la existencia de dos tipos de Lilith: la vieja, esposa de Samael, y la joven, mujer de Asmodeus, el rey de los demonios ${ }^{23}$.

Al margen de la Cábala, otras leyendas populares relacionan a Lilith con una de las dos prostitutas de Salomón, en línea con la tradición de que el rey Salomón tenía poder sobre los demonios ${ }^{24}$, e incluso sugieren su identificación con la reina de Saba ${ }^{25}$. También tuvo gran difusión la tradición según la cual el profeta Elías, de camino a la casa de una parturienta, se encuentra a Lilith.

En definitiva, las expresiones מלך בלהות ,עת צרה y פחד לילה constatan en la Biblia la existencia del miedo y el terror producido por distintas causas. A continuación me propongo rastrear los motivos que generan pánico y pavor en la literatura posterior. Ante las numerosas posibilidades que se ofrecían ante mí, me he visto en la

${ }^{21}$ Para el desarrollo de estas ideas, cf. J. DAN, «Samael, Lilith, 'and the Concept of Evil in Early Kabbalah», Association for Jewish Studies Review 5 (1980) págs. $17-40$.

${ }^{22}$ Cf. C. Gonzalo Rubio, La angeología en la literatura rabínica y sefardí (Barcelona 1977).

${ }^{23}$ Cf. J. DAN, «Samael, Lilith ...» pág. 24.

${ }^{24}$ Sobre este aspecto véase la tesis doctoral de P. A. ToriJAno Morales, Salomón en la Antigüedad tardía: textos esotéricos en tradiciones judías, cristianas y gnósticas (Madrid 2001), y de modo especial el capítulo V dedicado a Salómon exorcista (págs. 67-122).

${ }^{25}$ Cf. «Lilith», en Encyclopedia Judaica, vol. 11 col. 248. 
necesidad de acotar el campo de trabajo. Mi investigación se ha centrado en la literatura apocalíptica -sobre todo en el ciclo de Enoc- y en la mística judía primitiva. Seguidamente presentaré algunas de las causas que generan miedo a los que emprenden el ascenso a los cielos. No pretendo hacer, por consiguiente, un análisis exhaustivo y pormenorizado del tema, sino una aproximación que permita apreciar los puntos de contacto entre algunos aspectos del miedo que aparecen en la Biblia y la literatura posterior.

\section{ESTUDIO TEMÁTICO}

La literatura de Hekhalot o de los Palacios se sitúa en los comienzos de la mística judía durante el periodo talmúdico, si bien los textos que nos han llegado han sido escritos varios siglos después. Son un conjunto de pequeños tratados redactados entre los siglos v y vi, que tienen como tema fundamental la contemplación del mundo de la Merkabah. Los motivos que aparecen en estos textos son subidas a los cielos, angeologías y fórmulas mágicas que permiten ascender a la contemplación de la visión divina. En estos textos se perciben importantes puntos de contacto entre la literatura de Hekhalot y la literatura apocalíptica ${ }^{26}$, como son los viajes al cielo del visionario, la visión del trono divino y los himnos que se entonan ante la presencia de la Merkabah. Por supuesto, existen diferencias. A modo de ejemplo podemos mencionar que en la literatura apocalíptica el visionario asciende a los cielos para conocer los secretos de los fenómenos de la naturaleza y para acceder a los planes de Dios sobre la historia, aspectos estos no relevantes en la literatura de Hekhalot.

La literatura mística judía insiste en los peligros que acechan al visionario y los miedos que experimenta en su ascenso a los palacios. El miedo que se apodera del místico o vidente es una característica recurrente en muchas de las visiones apocalípticas y místi-

\footnotetext{
${ }^{26}$ No hay que olvidar que el libro hebreo de Enoc o 3 Enoc forma parte de la literatura de Hekhalot. Por consiguiente, es necesario distinguir claramente entre 1 y 2 Enoc, que forman parte de la literatura apocalíptica, y 3 Enoc, también llamado Sefer Hekhalot, que es una obra pre-cabalista. Sobre la relación entre la literatura apocalíptica y la literatura de Hekhalot, cf. N. FERNÁNDEZ MARCOS, «Los orígenes de la mística y la cábala judías», en Cristianismo marginado. Rebeldes, excluidos, perseguidos. I: De los orígenes al año 1000, ed. R. Teja (Aguilar de Campoo - Madrid 1998) págs. 159-179.
} 
cas. Terror, miedo y pavor son consustanciales a este tipo de literatura. He agrupado bajo tres epígrafes algunos de los motivos que inspiran miedo en el ciclo de Enoc y en la literatura de Hekhalot, a saber: el terror ante el carro divino (imposibilidad de ver el rostro de Dios, descripción de la Šekinah y de su morada), el temor a los ángeles (Qeșfiel, los ángeles catigadores) y los peligros del ascenso (pruebas).

\section{II.1. El terror ante el carro divino}

En la literatura de Hekhalot aparece recogido el temor y el espanto que inspira la imagen de la Merkabah. Uno de los principales miedos que experimenta el vidente es el terror que se apodera de él ante la presencia del carro divino.

Así, en 1 Enoc 14,13-14 ${ }^{27}$, el texto más antiguo después del relato de Ezequiel, el protagonista siente pavor y describe esta sensación como sentir frío y calor a la vez: «Entré en esta casa que es ardiente como fuego y fría como granizo, y el miedo me obnubiló y el terror me sobrecogió. Caí de bruces temblando...».

El rostro de Dios no lo puede ver ningún hombre. Así, se nos dice: «y el aspecto del rostro del Glorioso y Excelso no puede verlo tampoco ningún hombre carnal» (1 Enoc 14,21). El propio Enoc dice de sí mismo: «aunque yo miraba con el rostro hacia abajo» (1 Enoc 14,25). La sola presencia de la divinidad produce terror, llegando en ocasiones al desmayo: «Caí de bruces, y toda mi carne se disolvió y mi espíritu se trastornó» (1 Enoc 71,11) ${ }^{28}$.

Todo aquel que mire el rostro de la divinidad será destruido:

«aquel que le mire será inmediatamente desgarrado; aquel que vea su belleza será vaciado como un cántaro» (Hekhalot Rabbati sec. 159, pág. 28; cf. también Hekhalot Zutarti sec. 356 y 102) ${ }^{29}$.

\footnotetext{
${ }^{27}$ Las traducciones de los libros de Enoc han sido tomadas de A. DíEz MACHO (ed.), Apócrifos del Antiguo Testamento, vol. 4 (Madrid 1984).

${ }^{28}$ Cf. 1 Enoc 60,2-3.

29 No existe una traducción al castellano de todos los textos que conforman la literatura de Hekhalot. P. SCHÄFER, en su obra El Dios escondido y revelado (Madrid 1995), traduce una selección de textos. A ellos me remito, indicando la página donde se encuentran, pues no es fácil localizarlos con la única referencia de la fuente.
} 
«los ojos de ninguna criatura pueden mirarlo: ni los ojos (de un hombre) de carne y hueso, ni los ojos de sus servidores. Pero a aquel que lo observa, lo contempla y ve exactamente, sus pupilas se le sobrecogen y se tuercen y sus pupilas lanzan y engendran antorchas de fuego. Y le queman y le abrasan...» (Hekhalot Rabbati, sec.102, págs. 31-32).

En 3 Enoc $22^{\mathrm{a}}$, 13-14 destacan el fuego ${ }^{30} \mathrm{y}$ otros elementos relacionados con él a la hora de describir cómo es la Šekinah:

«La Šekinah reposa sobre ellos, piedras de zafiro los rodean, columnas de fuego a sus cuatro costados y pilares de antorcha a sus flancos. Hay un zafiro a un lado y un zafiro a otro, y bajo los zafiros ardientes brasas de retama».

En 3 Enoc 37 se añaden otros aspectos, como el azufre, huracanes, seísmos y tempestades, lo que no deja lugar a dudas a la hora de manifestar cómo percibe el visionario la realidad divina:

«En los siete palacios permanecen cuatro carros de la Šekinah, y delante de cada uno hay cuatro campamentos de la Šekinah. Entre un campamento y otro fluye continuamente un río de fuego. Entre un río y otro hay nubes de resplandor que los rodean y entre nube y nube están plantadas columnas de azufre. Entre columna y columna hay ruedas llameantes que las rodean. Entre llama y llama hay depósitos de relámpagos que las rodean. Por detrás de los depósitos de relámpagos están las alas de huracán que los rodean. Por detrás de las alas de huracán están las cámaras de tempestad que las rodean. Detrás de las cámaras de tempestad hay vientos, ruidos, truenos, chispas (sobre) chispas, seísmos (sobre) seísmos que las rodean».

El lugar donde habita el todopoderoso inspira temor. Así, en Hekhalot Rabbati sec. 153, pág. 23: «porque sobre un alto y sublime, terrible y espantoso trono resides, en las salas del excelso palacio». En Ma'aseh Merkabah sec. 549, pág. 95 se dice:

«Has preparado tu trono con fuerza, poder, alabanza y cántico. Nubes de fuego apresuradas, que propagan terror, (y) ayudantes que instigan miedo, miles y miles de miles y miríadas de miríadas de miríadas, alaban y glorifican tu grande, poderoso y terrible nombre».

\footnotetext{
${ }^{30}$ También se desarrolla este motivo en Ma'asé Merkabah. Cf. P. SCHÄFER, El
} Dios escondido, pág. 92. 
La morada de la divinidad está formada por lenguas de fuego, granizo y relámpagos. El espacio comprendido entre las plantas de los pies de las hayyot -las cuatro bestias que sustentan el carro o Merkabah-y Dios en el trono de su gloria se describe en Hekhalot Zutarti sec. 356, págs. 77-78 en términos de granizo, piedras de fuego de retama, piedras de berilio, nubes de consolación, filas de santos, espíritus y Lilin.

\section{2. El temor a los ángeles}

También los ángeles ocasionan miedo. El propio aspecto de los ángeles con los que se encuentra el vidente en su ascenso es perturbador. Hechos de materia ígnea y con aspecto humano, en ocasiones se aparecen como guerreros armados con arcos y flechas. La descripción de Kerubiel Yahvéh en 3 Enoc 22,2-4 nos sirve a modo de ejemplo:

«.... Ante su cólera tiembla el orbe, ante su ira se conmueven los campamentos, los cimientos se tambalean por temor a él y a su admonición Arabot se estremece. Su cuerpo en toda su extensión está lleno de brasas; su estatura es como la altura de los siete cielos; y su volumen como el volumen de los siete cielos. La abertura de su boca es como una antorcha ígnea; su lengua es fuego devorador; sus párpados como el resplandor del relámpago, y sus ojos como chispas fulgurantes. El aspecto de su rostro es cual fuego ardiente».

La misión de los ángeles es, por una lado, proteger la esfera divina de aquellos que no están autorizados e intentan penetrar en ella y, por otro, ayudar a aquellos que son dignos de ver la presencia de Dios. Sobresale en este sentido el ángel Qeșiel, cuyo nombre significa cólera de Dios. Existen ligeras variantes sobre el lugar donde se encuentra. Mientras en Hekhalot Rabbati 18,5-6 ${ }^{31}$ es uno de los dos ángeles guardianes de la puerta del sexto palacio, en 3 Enoc 1,3 custodia las puertas del séptimo cielo.

${ }^{31}$ No existe unanimidad a la hora de citar los textos de la literatura de los Palacios. P. SCHÄFER ha editado los textos en hebreo y los presenta en secciones: cf. Synopse zur Hekhalot-Literatur (Tübingen 1981). I. GRUENWALD, en cambio, siguiendo a G. SCHOLEM en Jewish Gnosticism, Merkavah Mysticism, and Talmudic Tradition (2 $2^{\mathrm{a}}$ ed. New York 1965), los organiza en capítulos. He preferido reflejar las citas manteniendo el criterio de sus respectivos autores, asumiendo que ello ocasiona una cierta incoherencia en la forma de citar los textos de Hekhalot en el artículo. 
Qeșfiel lleva en su mano una espada muy poderosa que despide rayos y grita «destrucción» e impide a los yordê Merkabah -término que se emplea en la literatura de los palacios para designar a los que emprenden el camino hacia la divinidad-el ascenso hasta que realicen una serie de pruebas.

También se mencionan los ángeles castigadores o ángeles de la destrucción, encargados por Dios de cumplir su sentencia: «Y los entregará a los ángeles castigadores, para que paguen por cuanto oprimieron a sus hijos y a sus elegidos» (1 Enoc 62,11). Y se nos dice de ellos que recogen instrumentos de hierro y bronce para castigar con ellos a los reyes y poderosos ${ }^{32}$. Sin embargo, hay que destacar que estos ángeles no son seres malvados ${ }^{33}$, sino que muestran un extraordinario celo para evitar que personas no aptas alcancen a ver el trono de Dios.

\section{3. Los peligros del ascenso}

Otro punto a tratar es el miedo que experimenta el adepto en su ascenso y las pruebas a las que se ve sometido por los ángeles para evitar que asciendan personas no adecuadas.

En 2 Enoc 19, dos hombres ${ }^{34}$ acompañan a Enoc en su ascenso por los cielos. Al llegar al séptimo cielo donde están los seres celestiales (arcángeles, querubines, etc.), dice: «cogí miedo y me puse a temblar, lleno de congoja». Tras mostrarle a lo lejos al Altísimo lo dejan solo. «Así, pues, me quedé solo en los confines de la tierra y lleno de angustia caí sobre mi rostro y me dije a mí mismo: ¡Ay de mí! ¿Qué es lo que me acaba de suceder?»(v.6). A pesar de que los arcángeles le instan a no temer, prosigue: «¡Ay de mí! Señor mío, que mi alma ha huido de mí, (presa) del temor y la angustia» (v.8).

${ }^{32}$ Cf. 1 Enoc 56,1ss; 63,1.

33 Hay que distinguir los ángeles de la destrucción que aparecen en la literatura de Hekhalot de los arcontes del gnosticismo. Aunque a primera vista pueda parecer que existen ciertas semejanzas entre ambos, lo cierto es que los arcontes intentaban capturar el alma de la persona redimida e impedirle ascender a la fuente de luz, mientras que los ángeles, celosos de mantener a la divinidad en las alturas, intentan evitar el ascenso de los no aptos. Cf. I. GRUENwALD, Apocalyptic and Merkavah Mysticism (Leiden - Köln 1980) pág. 111.

${ }^{34}$ Conviene recordar que en la literatura enóquica los ángeles son representados como hombres. 
Los textos de Hekhalot subrayan los peligros del ascenso, pues para alcanzar el trono de Dios el místico debe pasar por siete puertas guardadas por terribles ángeles. Para poder franquear las puertas ha de tener en su poder los sellos mágicos, así como conocer los nombres de los ángeles. De este modo los ángeles someten a pruebas al adepto. Los castigos que infligen a los no capacitados son terribles: golpes con barras de hierro, lanzamiento de piedras, empujones a ríos de lava ardiendo, etc.

Por poner un ejemplo, el visionario sólo puede acceder al sexto palacio tras haber sido invitado dos veces. Si entra tras la primera invitación, los ángeles le arrojan trozos de hierro:

«Cuando es digno de descender a la Merkavá, cuando (los ángeles) le dicen:

'ientra!', (pero) no entra (inmediatamente),

y de nuevo le dicen:

'¡entra!'.

Y él (entonces) inmediatamente entra, (entonces) le alaban (y dicen):

'seguro, este es (uno) de los yored merkavá'.

Pero si no es digno de descender a la Merkavá,

(y) le dicen:

'¡entra!',

y él (inmediatamente entra),

(entonces) le lanzan inmediatamente trozos de hierro».

(Hekhalot Rabbati sec. 258, pág. 51)

En otra ocasión los guardianes del trono arrojan miles y miles de olas de agua. En realidad, es un efecto visual porque no hay agua, sino que es el espejismo que produce el mármol del palacio. El que proclamaba su miedo es castigado con miles y miles de trozos de hierro ${ }^{35}$.

En definitiva, no es aventurado afirmar que, en lo relativo al tratamiento literario del miedo y de las sensaciones que provoca, existe una cierta continuidad entre la Biblia y la literatura judía posterior. La literatura apocalíptica y la de Hekhalot desarrollan

${ }^{35}$ Hekhalot Rabbati, sec. 259. 
una imaginería del miedo en términos similares. La descripción de la morada divina y de la propia Šekinah, el aspecto de los ángeles, los sentimientos que originan en el visionario el ascenso a los cielos, etc., se reflejan utilizando los mismos motivos. Este es un aspecto más a tener en cuenta a la hora de subrayar los puntos de contacto entre ambas literaturas.

\section{RESUMEN}

El propósito de este artículo es analizar algunas expresiones bíblicas de miedo y terror e investigar su relación con el ámbito de la mística y de la apocalíptica, percibiendo desarrollos distintos de un mismo motivo. La primera parte se dedica a estudiar las expresiones: מלך בלהות ,עת צרה (Iob 18,14) y פחר לילה (Ps 91,5) desde un punto de vista filológico y mitológico. La segunda parte está centrada en el estudio temático de estos tópicos en la literatura de Hekhalot y en el ciclo de Enoc, sobresaliendo como temas destacados -aunque no sean los únicos- el terror ante el carro divino, el temor a los ángeles y los peligros del ascenso.

\section{SUMMARY}

The aim of this paper is to analyze a few biblical expressions of fear and terror and study their relationship with apocalyptic and mystic environments. It is divided in two parts: first, I examine the terms מלך בלהות ,עת צרה (Iob 18:14), and פחר לילה (Ps 91:5) from both a philological and mythological point of view. And second, I present these topics in Hekhalot literature and the Enoch cycle stressing three basic aspects, namely the fear inspired by the divine chariot, the dread to the angels, and the risks of heavenly ascensions. 